\title{
Ground subsidence geo-hazards induced by rapid urbanization: implications from InSAR observation and geological analysis
}

\author{
F. Chen ${ }^{1}$, H. Lin ${ }^{1}$, Y. Zhang ${ }^{1}$, and Z. Lu ${ }^{2}$ \\ ${ }^{1}$ Institute of Space and Earth Information Science, The Chinese University of Hong Kong, ShaTin, N.T., Hong Kong, China \\ ${ }^{2}$ US Geological Survey, Cascades Volcano Observatory, Vancouver, WA 98683-9589, USA \\ Correspondence to: H. Lin (huilin@cuhk.edu.hk)
}

Received: 29 November 2011 - Revised: 14 January 2012 - Accepted: 18 January 2012 - Published: 12 April 2012

\begin{abstract}
Due to the convenient transportation and construction, cities are prone to be situated in areas with flat terrain and unstable sediments, resulting in the concurrence of ground subsidence and urbanization. Here the interaction between geology, anthropogenic processes and ground subsidence geo-hazards were investigated in the Greater Pearl River Delta region of China. Geological evidences and 2006-2010 persistent scatterer data indicate that anthropogenic activities are dominant, although the distribution of river system and Quaternary sediments are also highly related to significant displacements (primarily at a rate of -15 to $15 \mathrm{~mm} \mathrm{a}^{-1}$ ). The surface displacements derived by synthetic aperture radar interferometry suggest that the urbanization rhythm has to be routinely monitored. Considering analogous urbanization modes, particularly in developing countries, ground subsidence monitoring together with the analysis of its driving force are critical for geo-hazards early-warning, city planning as well as sustainable urbanization.
\end{abstract}

\section{Introduction}

Urbanization is a global trend, particularly in developing countries because of the productivity rise in dense agglomerations. Apart from advantages, e.g. closeness, lower carbon emission (Glaeser, 2011); urbanization is faced with challenges, including contagious disease and congestion. The acceleration of urbanization has enhanced human influence on the natural environment, requiring a detailed insight into the limitations on development that will enable us to avoid manmade disasters. For the convenient transportation and construction, cities are prone to be situated in flat areas accompanied by well-developed sediments, particularly in the vicinity of rivers and coasts. Sediments deposited by flowing water or tide dynamics, as in a riverbed, flood plain or delta, are physically unstable. Ground subsidence geo-hazards have frequently occurred in cities situated on unconsolidated alluvial deposits or reclaimed regions resulting from creeping, compaction and infrastructure construction (Meckel et al., 2006; Raucoules et al., 2008; Kim et al., 2010).

In this study, the Greater Pearl River Delta (GPRD), representative of a fast urbanization region in alluvial and lacustrine deposits of the world, is investigated. The GPRD, comprising Hong Kong, Macao and the nine municipalities (Guangzhou, Shenzhen, Zhuhai, Dongguan, Zhongshan, Foshan, Huizhou, Jiangmen, and Zhaoqing) of Guangdong Province in mainland China, is one of the most densely urbanized regions and the main hub of China's economic growth. Since the launch of China's reform program in 1978, the GPRD has set several world records, e.g. the fastest growth in gross domestic product (GDP), from US $\$ 8$ billion in 1980 to US $\$ 100$ billion in 2001 as well as a population explosion in GPRD cities such as the fastest one, Shenzhen, whose population increased from around 30000 in 1980 to over 14000000 in 2011 - nearly 500 times. The rapid urbanization has exerted pressures (Karen et al., 2000; Zeng et al., 2008; Stone, 2009) on the sustainable development of the GPRD. Geo-hazards initiated by severe ground subsidence have been highlighted due to direct economic losses (3.47 billion RMB) and casualties (768 deaths) from 1994 to 2005 in the GRPD (Zhu et al., 2007). Interferometric synthetic aperture radar (InSAR) (Zebker et al., 1994; Jonsson et al., 2003), particularly the persistent scatterer interferomety (PSI) (Ferretti et al., 2001; Lanari et al., 2004; Tizzani et al., 2007; Lin et al., 2011), has proven to be powerful in determining a time series of displacements by exploiting stable, point-like radar targets with a large stack of SAR images (>15) (Hilley et al., 2004). 
Table 1. The Envisat ASAR data used in this study.

\begin{tabular}{|c|c|c|c|c|}
\hline \multirow{2}{*}{ No. } & \multicolumn{2}{|c|}{ Track 25} & \multicolumn{2}{|c|}{ Track 297} \\
\hline & $\begin{array}{r}\text { Acquisition } \\
\text { time }\end{array}$ & Orbits & $\begin{array}{r}\text { Acquisition } \\
\text { time }\end{array}$ & Orbits \\
\hline 1 & 6 Sep 2006 & 23626 & 19 Mar 2007 & 26403 \\
\hline 2 & 11 Oct 2006 & 24127 & 23 Apr 2007 & 26904 \\
\hline 3 & 28 Feb 2007 & 26131 & 28 May 2007 & 27405 \\
\hline 4 & 4 Apr 2007 & 26632 & 2 Jul 2007 & 27906 \\
\hline 5 & 9 May 2007 & 27133 & 6 Aug 2007 & 28407 \\
\hline 6 & 13 Jun 2007 & 27634 & 10 Sep 2007 & 28908 \\
\hline 7 & 18 Jul 2007 & 28135 & 15 Oct 2007 & 29409 \\
\hline 8 & 22 Aug 2007 & 28636 & 19 Nov 2007 & 29910 \\
\hline 9 & 31 Oct 2007 & 29638 & 12 May 2008 & 32415 \\
\hline 10 & 9 Jan 2008 & 30640 & 16 Jun 2008 & 32916 \\
\hline 11 & 13 Feb 2008 & 31141 & $21 \mathrm{Jul} 2008$ & 33417 \\
\hline 12 & 19 Mar 2008 & 31642 & 25 Aug 2008 & 33918 \\
\hline 13 & 23 Apr 2008 & 32143 & 29 Sep 2008 & 34419 \\
\hline 14 & 2 Jul 2008 & 33145 & 3 Nov 2008 & 34920 \\
\hline 15 & 15 Oct 2008 & 34648 & 8 Dec 2008 & 35421 \\
\hline 16 & 19 Nov 2008 & 35149 & 12 Jan 2009 & 35922 \\
\hline 17 & 24 Dec 2008 & 35650 & 16 Feb 2009 & 36423 \\
\hline 18 & 28 Jan 2009 & 36151 & 27 Apr 2009 & 37425 \\
\hline 19 & 8 Apr 2009 & 37153 & 1 Jun 2009 & 37926 \\
\hline 20 & 13 May 2009 & 37654 & 10 Aug 2009 & 38928 \\
\hline 21 & 17 Jun 2009 & 38155 & 17 Sep 2009 & 39429 \\
\hline 22 & 22 Jul 2009 & 38656 & 19 Oct 2009 & 39930 \\
\hline 23 & 28 Aug 2009 & 39157 & 23 Nov 2009 & 40431 \\
\hline 24 & 30 Sep 2009 & 39658 & 28 Dec 2009 & 40932 \\
\hline 25 & 13 Jan 2010 & 41161 & 1 Feb 2010 & 41433 \\
\hline 26 & 17 Feb 2010 & 41662 & 8 Mar 2010 & 41934 \\
\hline 27 & 24 Mar 2010 & 42163 & 12 Apr 2010 & 42435 \\
\hline 28 & 24 Apr 2010 & 42664 & 17 May 2010 & 42936 \\
\hline 29 & 2 Jun 2010 & 43165 & 21 Jun 2010 & 43437 \\
\hline 30 & 7 Jul 2010 & 43666 & 26 Jul 2010 & 43938 \\
\hline 31 & 11 Aug 2010 & 44167 & & \\
\hline
\end{tabular}

Although several PSI studies were conducted (Zhao et al., 2009; Chen et al., 2010), they focused on a single city and left major gaps in terms of spatial coverage of the GPRD. Nowadays, the GPRD is integrated as a whole because of the geological environment as well as economic and policy coordination. Furthermore, the large-scale displacement trend only can be detected by investigating the entire agglomeration. Otherwise, hot-spots for potential geo-hazards can easily be left out. To address this issue and understand the exact principle of motion (local-scale and large-scale), it is essential to estimate the ground displacement and its time series for geo-hazards early-warning related to fast urbanization, via the analysis of motion spatial heterogeneity or using displacement thresholds based on engineering specifications.

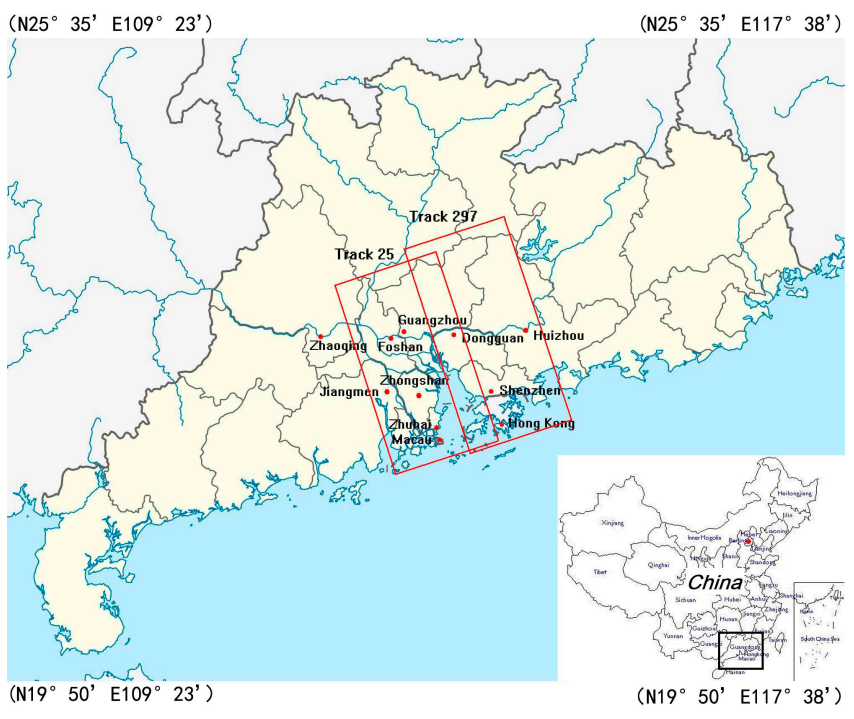

Fig. 1. Location of the Greater Pearl River Delta (GPRD) region, comprising Hong Kong, Macao and the nine municipalities of Guangdong Province. Two ascending tracks of Envisat ASAR data (Tracks 25 and 297), marked by red rectangles, are analyzed for surface settlement inversion covering the whole GPRD region except for Zhaoqing City.

\section{Data and methodology}

In total, 61 Envisat ASAR single look complex (SLC) images from two ascending tracks in image swath 2 mode (31 from Track 25 and 30 from Track 297), as listed in Table 1, were used to cover most urban regions of the GPRD (except for Zhaoqing City) of approximately $150 \times 200 \mathrm{~km}^{2}$; the area extends from $109^{\circ} 23^{\prime}$ to $117^{\circ} 38^{\prime} \mathrm{E}$ and from $19^{\circ} 50^{\prime}$ to $25^{\circ} 35^{\prime} \mathrm{N}$ (Fig. 1). All the ASAR images used in this work were acquired at the Hong Kong Remote Sensing Ground Receiving Station, which was established at the Chinese University of Hong Kong in 2006. The pixel spacing was $7.80 \mathrm{~m}$ in the range direction, and $4.05 \mathrm{~m}$ in the azimuth direction. DORIS precise orbits data provided by the ESRIN Help desk of ESA were applied to calculate interferometric perpendicular baselines. The 3-arcsecond $(\sim 90 \mathrm{~m})$ Shuttle Radar Topography Mission (SRTM) (Farr and Kobrick, 2000) DEM data from the United States Geological Survey (USGS) were used for topographic phase estimation at the first step, and then for geocoding the InSAR products (transforming Range-Doppler coordinates into Universal Transverse Mercator map geometry system) were used.

When the temporal image co-registration was completed, interferograms were generated by conjugate multiplication of complex image pairs. The small baseline strategy (smaller than $350 \mathrm{~m}$ spatially and 3 months temporally) was applied in this procedure, resulting in high coherence. The corresponding interferogram formation graphs are illustrated in 
a

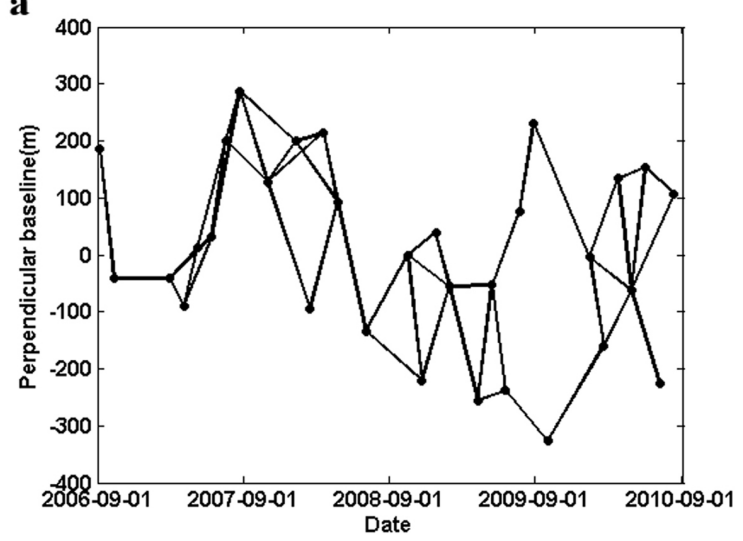

b

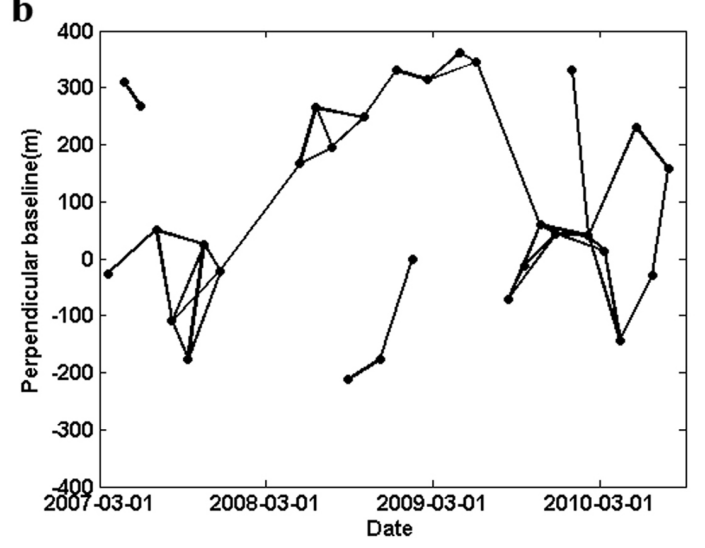

Fig. 2. Baseline-time plots relevant to the ASAR images and interferograms used in this study; (a) Track 25, (b) Track 297.

Fig. 2a (Track 25) and Fig. 2b (Track 297), respectively. Effects of flat terrain were estimated by the DORIS precise orbits data, and the topography phases were removed using the above mentioned SRTM DEM data. We used an improved PSI model developed from interferometric point target analysis (IPTA) to analyse the effects of urbanization in the GRPD, and to expose the possible geo-hazards of this runaway growth in population and industry. Generally, the PSI implementation exploits the temporal and spatial characteristics of interferometric signals collected from point-likely or high coherent targets (referred to as PS candidates hereafter for simplicity), and allows a precise estimation of deformation, topographic phase and other parameters. The PS candidates were determined by two selection criteria in this study. One was based on the spectral properties of each single SLC image; the other was derived by utilizing the average spatial coherence of all generated interferograms. In such a way, several distributed scatterers (DS) (Ferretti et al., 2011) showing similar reflectivity and coherence values could also be extracted to increase the density of PS candidates. Phase unwrapping was performed in the spatial domain using a minimum cost-flow (MCF) algorithm for sparse data (Costantini and Rosen, 1999). Then

the $i$-th unwrapped interferometric phase $\phi_{x, i}$ at the location $x$ is the sum of topographic phase $\phi_{\mathrm{topo}, x, i}$, ground deformation phase $\phi_{\mathrm{def}, x, i}$, differential atmospheric phase $\phi_{\mathrm{atm}, x, i}$ and phase noise $\phi_{\text {noise }, x, i}$ :

$\phi_{x, i}=\phi_{\mathrm{def}, x, i}+\phi_{\mathrm{topo}, x, i}+\phi_{\mathrm{atm}, x, i}+\phi_{\text {noise }, x, i}$

The whole deformation rates along line of sight (LOS) from September 2006 to August 2010 were estimated by the improved PSI model, negative for subsidence, i.e. the motion of the ground away from satellite. Several key points, including residual orbits phase estimation, atmospheric phase screen mitigation, and large-scale displacement inversion with single-reference point, have been mastered:

- residual orbits phase was initially estimated on the differential interferogram fringe and SLC image coregistration offsets, then a 2-D quadratic model phase function is employed for global phase trend removal;

- global component of atmospheric phase screen has been partially mitigated using the above 2-D quadratic model; the residual component was further eliminated by filters in space-temporal domain during regression;

- the density of measurement points increased thanks to the small baseline strategy; high density PS candidates guarantee the successful implementation of large-scale deformation inversion using a single-reference point (located in stable old towns and selected by manual) for each frame.

The main steps of the improved PSI are summarized as follows: first, a simulation model based on singular value decomposition (SVD) was used for $n$ differential phase time series retrieval (single-reference stack). Then, a twodimensional regression based on a linear deformation model was applied on the baseline and acquisition time interval domain to estimate the residual height $\varepsilon$ and linear displacement rate $v$ by maximizing the following equation (Ferretti et al., 2001):

$\Gamma(v, \varepsilon)=\left|\frac{1}{n} \sum_{i=1}^{n} e^{j\left(\phi_{x, i}-\phi_{\mathrm{def}, x, i}-\phi_{\mathrm{topo}, x, i}\right)}\right|$

The temporal ensemble coherence $(\Gamma)$, ranging from 0 to 1 , was considered as a reliability measure in fitting the predefined displacement model. Finally, the atmospheric phase, non-linear displacement and error terms of the residual phase were further discriminated utilizing their different spatial and temporal dependencies. The derived accuracy of PSI model could reach as high as 1 to $2 \mathrm{~mm} \mathrm{a}^{-1}$ (Teatini et al., 2005; Stramondo et al., 2008) with satisfying long time spanning, e.g. approximate $5 \mathrm{yr}$ in this investigation; however, the evaluation of the error also depends on the specific data used, pre-processing, time interval, and observed scenarios. Compared with the conventional PSI processing approach, except 


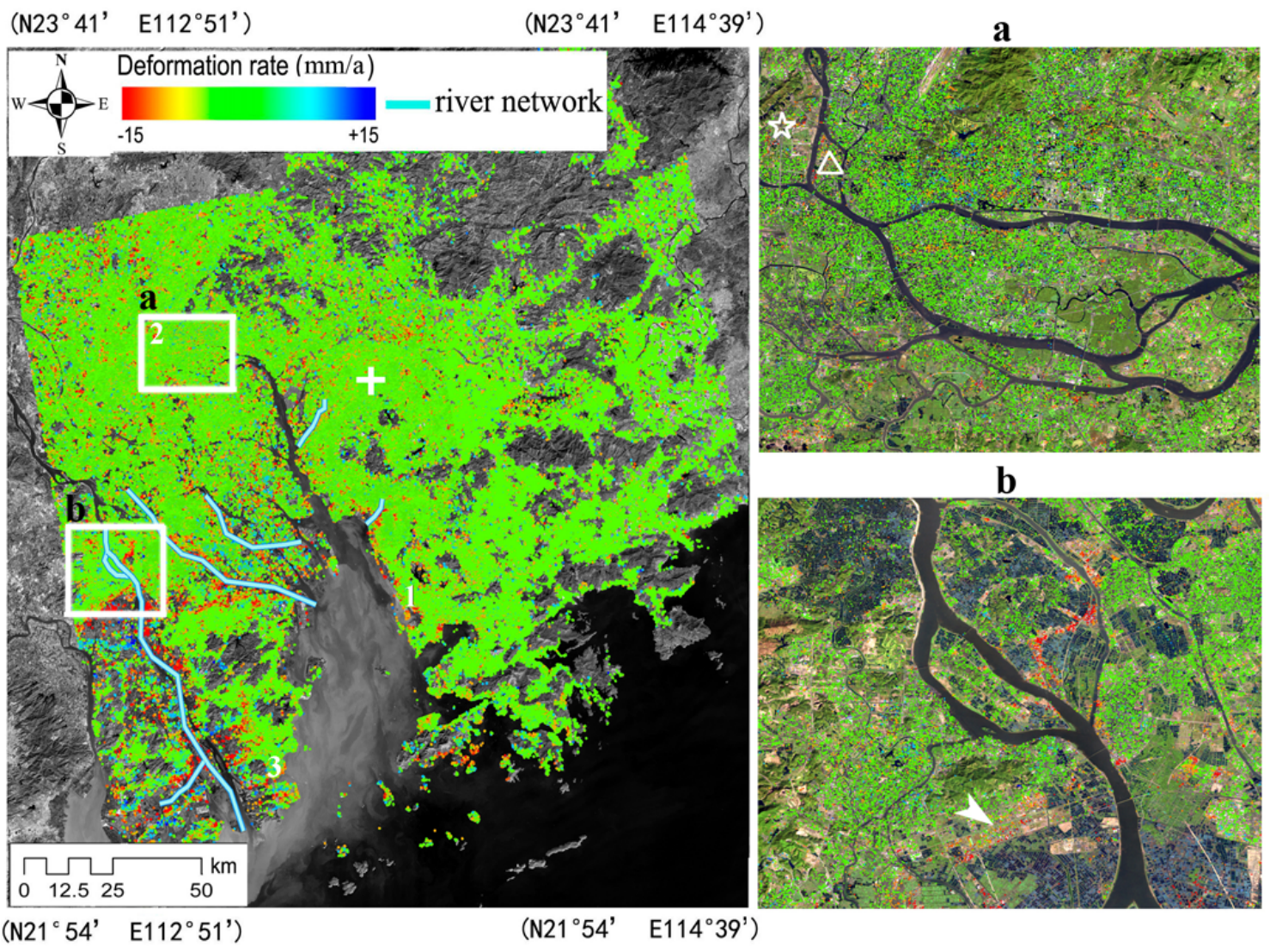

Fig. 3. Annual surface displacement rates over the GPRD (marked by red rectangles in Fig. 1) derived by Persistent Scatterer Interferometry (PSI) model, overlapped on a SPOT remote sensing image. The primary values are in the range of $-15 \mathrm{~mm} \mathrm{a}^{-1}$ to $15 \mathrm{~mm} \mathrm{a}^{-1}$ in the span of $2006 \sim 2010$, and the significant displacements are located along the river network, marked by the blue line (derived by manual using the SPOT 5 image interpretation). Two detailed displacement images (a) Guangzhou (b) Jiangmen combined with field investigations demonstrate that the settlements have close relationship with anthropogenic activities. The white cross indicates the reference point for the integrated whole velocity field; symbols of pentagram, triangle and arrow indicate the locations of ground collapse accidents in 2007-2008, ground instability by the high-speed railway track in 2010, and Jiang men new development zones built in the last $10 \mathrm{yr}$, respectively. The numbers "1, 2 and 3" indicate the locations of PS time series in Fig. 5a, b and c.

for urban areas, the proposed PSI model is feasible for largescale natural regions monitoring thanks to the enhanced spatial density of PS candidates, which is similar to the newly developed SqueeSAR algorithm (Ferretti et al., 2011). Moreover, the improved PSI is more efficient than SqueeSAR because of its straightforward procedures at cost of resolution and accuracy loss jointly determined by the spatial averaging and phase unwrapping.

\section{Results and analysis}

\subsection{Deformation field}

Two stacks of SAR data were processed separately, than the results were integrated using the common PS candidates in the overlap region. That is, the motion values from the corresponding frame (Track 297) were calibrated based on the reference frame (Track 25). The final derived velocity field shows no large-scale subsidence bowls; however, local displacement regions of several square kilometres occurred over the study site. The corresponding values are primarily in the range of $-15 \mathrm{~mm} \mathrm{a}^{-1}$ to $15 \mathrm{~mm} \mathrm{a}^{-1}$. With the least square strategy, the velocity offset and standard deviation (also referred to as relative accuracy) between the two adjacent tracks were estimated, presenting $2.35 \mathrm{~mm} \mathrm{a}^{-1}$ and $3.18 \mathrm{~mm} \mathrm{a}^{-1}$, respectively. It is clear that the displacements are located along the Pearl River, as marked by the blue line (interpreted by manual using the SPOT 5 image) in Fig. 3. The GPRD is formed by three major branches of the Pearl River: the Xi Jiang, Bei Jiang and Dong Jiang, and is comprised of two alluvial deltas separated by the main stream of the Pearl River. Due to the combination of fluvial outwash and tide dynamics, the depth of the silt layer is approximately $15-40 \mathrm{~m}$. This kind of sediment or alluvial deposit, with a high compressibility, low permeability and bearing capacity, 
can be unstable when external forces are applied, easily leading to ground deformation damage, foundation sinking, as well as seismic subsidence (Zhao et al., 2009). The association of higher ground subsidence with the geology indicates that the clay deposits are unstable and alluvial outwash dynamics can play a role in the surface displacement following alternating drought-flood seasons. This physical mechanism may be the cause of building collapse along the He Jiang in August 2010, Zhaoqing City. Signatures of the uplift are jointly determined by the alluvial accumulation, phase errors from residual height and unwrapping procedures.

Figure $3 \mathrm{a}$ and $\mathrm{b}$ shows the detailed surface displacements of the Guangzhou and Jiangmen urban areas. Field investigations of the past few years demonstrate that the spatial distribution of surface deformation in Guangzhou has a close relationship with human activity, including underground civil projects, construction of factories, and the expansion of development zones. Geo-hazards, including ground collapse, debris flow and building damage, occurred frequently within the subsidence zones. In 2007-2008, six ground collapse accidents fell within the subsidence region induced by the construction of metro lines (Zhao et al., 2009), marked by the white triangle in Fig. 3a; in 2010, tens of buildings in Jinshazhou, Guangzhou were seriously damaged by local ground subsidence induced by the high-speed railway underground project, resulting in an economic loss of 30 million RMB, marked by the white pentagram in Fig. 3a. The location of deformation zones in Jiangmen City corresponds with the urban expansion pattern of the last $10 \mathrm{yr}$; that is, approximately $80 \%$ of subsidence areas are located in new development zones, implying induced consolidation of the soft soil during and after completion of the construction projects as the cause, marked by the white arrow in Fig. 3b. In addition, the elongated pattern of significantly moving PS corresponds with the location of the river network, which is partially determined by the more compressible deposits resulting from the fluvial outwash.

\subsection{Deformation vs. Quaternary geology}

Apart from anthropogenic activity, Quaternary geology is another prominent factor. The Pearl River basin was originally formed in the northern and central parts of the present delta as a result of faulting. During the Quaternary, a large amount of silt was deposited in the mouths of the Xi Jiang, Bei Jiang, and Dong Jiang, and eventually formed the composite GPRD (Weng, 2007). The NE-SW, NW-SE, and E-W faults intersect, arranging the geological structural units into a chessboard pattern, where the limestone corrosion fractures and the Karst caves are gestated. Taking Guangzhou City as an example, Fig. 4 shows that it is not clear whether the group of faults (Guangzhou-Conghua) in the urban area is related to the distribution of significant subsidence (extracted by a pre-defined threshold $<-8 \mathrm{~mm} \mathrm{a}^{-1}$ ), but it is highly related to the distribution of Quaternary sediments, especially to the boundary of Quaternary sediments and Tertiary rocks, see Sects. 1 and 2 of $N_{1}$ and Sect. 3 of $P_{z 1}$; many faster displacement points are located along the transition belts of different geological units. The profile sections of $a-b$ and $c-d$ demonstrate the correlation between the boundaries of rock distribution and PS deformation velocities. Note that the PS deformation rates in the profiles are derived from the original velocity field without the threshold filtering. Assuming identical external pressures, different sediments with different porosities can induce uneven displacement trends, which should be taken into account during city planning.

\subsection{Analysis of driving forces}

The driving forces of surface displacement are rather complicated, not even completely understood at present, owing to the diversity of anthropogenic activities, runoff and geology in large-scale urban agglomerations. Figure 4 shows that the displacement field and the geological structural units are weakly interrelated, implying that there was no obvious tectonic motion during the period of observation. Field investigation demonstrates that outwash dynamics and anthropogenic activities interact sometimes, although the latter plays a more significant role, including urban expansion, reclamation, infrastructure construction and underground water pumping, etc. In general, different driving forces correspond to diverse geological deformation modes, e.g. aquifer overexploitation links quadratic or linear sinking, exponential settlement links land reclamation, and sudden deformation links engineering construction. Consequently, the characteristics of historical LOS displacements from InSAR observations allow us to discriminate those external forces via geological deformation modes vs. PS motion time series (Fig. 5). New development or reclamation zones accelerate the compression and creeping of silt layers because of the downward pressure induced by buildings or other infrastructures, resulting in severe surface subsidence $\left(-25.2 \mathrm{~mm} \mathrm{a}^{-1}\right)$ at the primary consolidation stage; this phenomenon can be explained by the Terzaghi theory (Terzaghi and Peck, 1967). However after another $2 \sim 3 \mathrm{yr}$, secondary compression occurs and the surface displacement is nearly in balance (Fig. 5a). The surface subsidence triggered by infrastructure construction has a close relationship to the project period (Fruneau and Sarti, 2000); compared with remarkable subsidence during the working period $\left(-31.3 \mathrm{~mm} \mathrm{a}^{-1}\right)$, the surface is relatively stable before and after the completion of a project, demonstrating cascaded motions (Fig. 5b). Industry zones need a large volume of fresh water for the manufacturing process. Groundwater overexploitation changes the local water table (Raucoules et al., 2008), which results in settlement and damage to neighbourhood buildings or sewage systems. Figure $5 \mathrm{c}$ shows a continual decline of $-18.41 \mathrm{~mm} \mathrm{a}^{-1}$. 


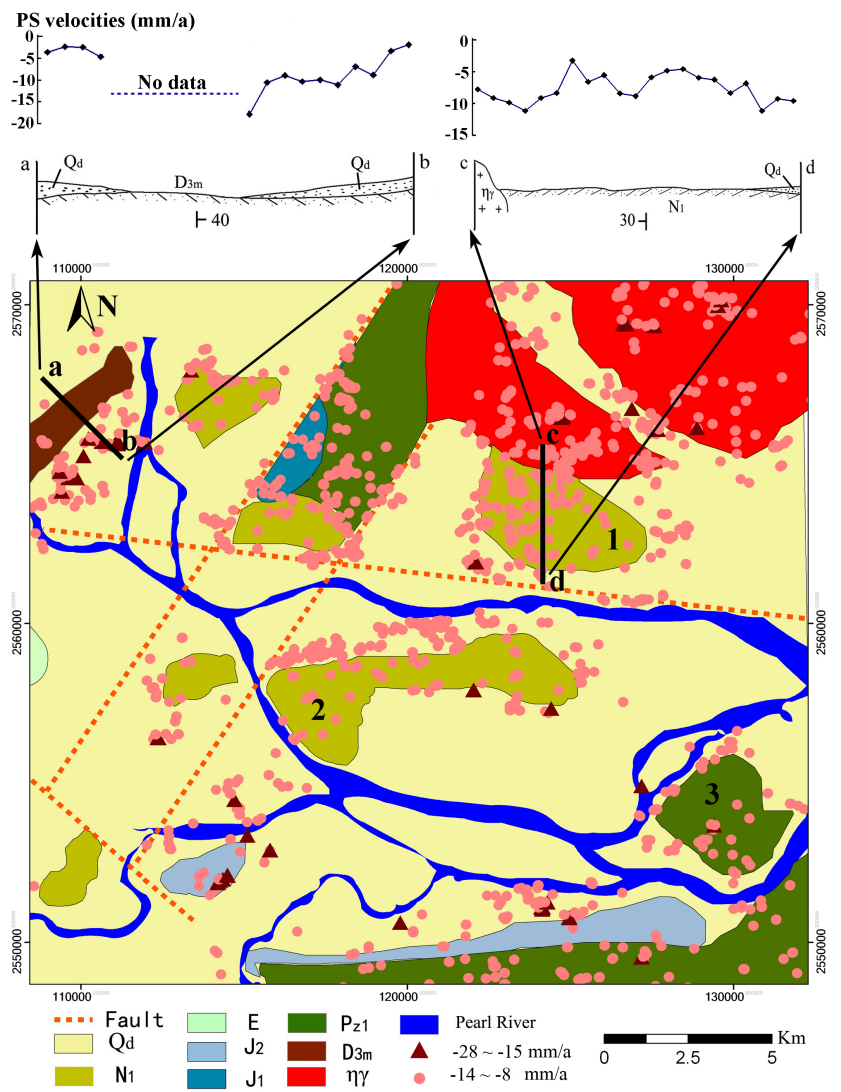

Fig. 4. Geological relationship with ground displacement in Guangzhou, covering same area as Fig. 3a. Instead of the two groups of faults, the distribution of Quaternary deposits, especially to the boundary of Quaternary sediments and late Tertiary rocks, is highly related to significant displacements $\left(<-8 \mathrm{~mm} \mathrm{a}^{-1}\right)$ validated by the results in Guangzhou $\left(Q_{\mathrm{d}}\right.$ : Quaternary deposits, including gravel, sand and clay; $N_{1}$ : Neogene-Miocene conglomerate, sandstone and shale; $E$ : Paleogene-Eocene conglomerate, sandstone and limestone; $J_{2}$ : Jurassic-middle conglomerate, sandstone and shale; $J_{1}$ : Jurassic-early conglomerate, sandstone and shale; $P_{z 1}$ : Permian-late shale, sandstone and siltstone; $D_{3 \mathrm{~m}}$ : Devonian-late sandstone, shale and siltstone; $\eta \gamma$ : mica granite during Yanshanian period between Jurassic and early-Cretaceous). The profile sections of $\mathrm{a}-\mathrm{b}$ and $\mathrm{c}-\mathrm{d}$ are examples of rock distribution, geological and the PS deformation velocities relationships, demonstrating the correlation between the boundary of different geological units (i.e. Quaternary distribution or old rocks) and significant displacement trends.

\section{Discussion and conclusion}

In the past $30 \mathrm{yr}$, starting with new cities called "Special Economic Zones" established next to Hong Kong and Macau, the spatial mode of rural urbanization in the GPRD has evolved from "micro-centralization and macro-dispersal" to "macrocentralization and micro-dispersal". The polycentric mega urban region around the estuary of the Pearl River has risen to dominate the landscape from Hong Kong to Guangzhou $\mathbf{a}$

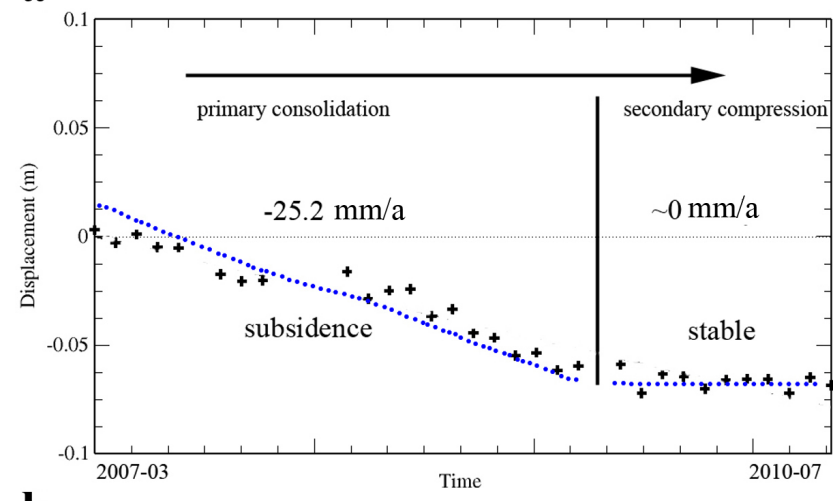

b

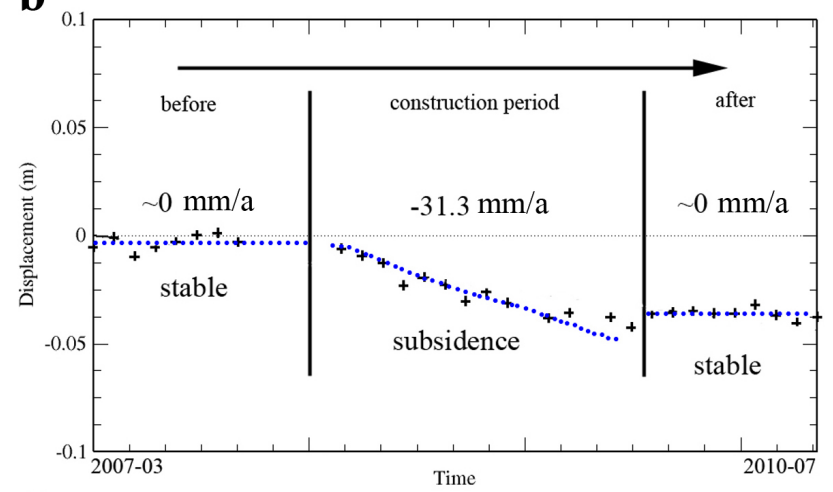

c

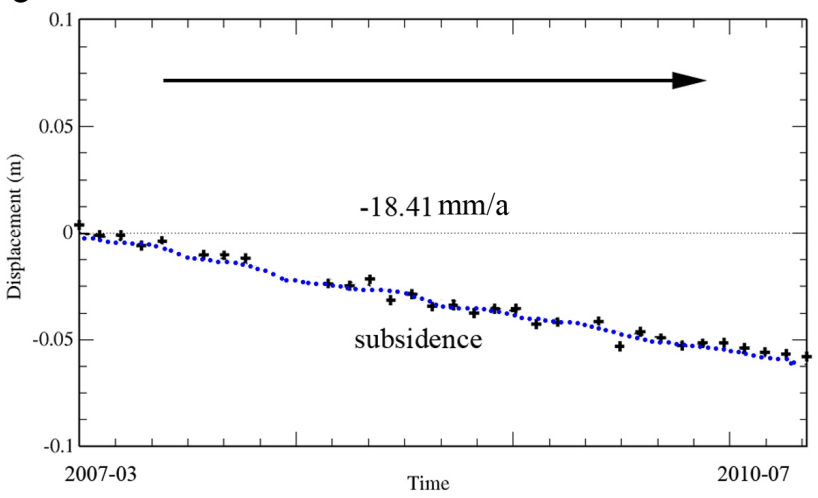

Fig. 5. Driving force discrimination conducted by the comparison between PS displacement time series and geological deformation modes; (a) a reclamation mode, the subsidence rate can reach as high as $-25.2 \mathrm{~mm} \mathrm{a}^{-1}$ during the primary consolidation compared with approximately zero in the secondary compression stage; (b) an infrastructure construction mode, the historical displacements are cascaded, demonstrating close relationship with the construction period; (c) a groundwater overexploitation mode, the surface subsidence is ongoing with an average rate of $-18.41 \mathrm{~mm} \mathrm{a}^{-1}$ during the whole observation span.

and Foshan in the northwest and then through Zhongshan down to Zhuhai and Macau in the southwest. Since 2005, the shortage of land in the urban centers of the GPRD has triggered urban sprawl from land reclamation and rural urbanization, which in turn shifts the infrastructure activities from the 
inner cities to those "micro-dispersal" suburban or development districts. The newly developed towns and displacement zones need extra attention by city planners to avoid underlying geo-hazards.

The frequent concurrences of ground subsidence geohazards and fast urbanization have been the focus of modern society, and thus feasible monitoring solutions are imperative. Our study demonstrates an improved PSI method that can resolve detailed ground settlements for the urbanization process. The results in GPRD show that potential geo-hazards related to surface displacement can be precisely detected by the space-based InSAR technology. Although the driving forces of ground settlements are complicated, it is possible to discriminate some of them by using the time series analysis. We conclude that anthropogenic influences are the determinant for the ground subsidence geo-hazards in the GPRD. The distribution of river system and Quaternary sediments is highly related to significant displacements, indicating the demand for geological investigation before future city planning, owing to the well-developed, overlying silt layers. Considering the analogous geological condition (e.g. sediments or alluvial deposits) and human behaviours (e.g. urban expansion, land reclamation and underground project construction), this study describes a potential geo-hazards early-warning approach under global urbanization by jointly considering the motion spatial heterogeneity and displacement thresholds based on engineering specifications. Excessively rapid urbanization not only induces pollution and places extra stress on the area's limited resources, but also causes serious ground subsidence, hampering the economic zone's sustainable development. Utilizing the close relationship between obvious surface displacement and geological disasters (Steven et al., 2003; Chen et al., 2010), improper anthropogenic activities (e.g. resource over-exploitation and low-quality infrastructure construction) should be avoided by governments through scientific management (Glaeser, 2011) to make agglomerations be the centre of productivity and pleasure.

Acknowledgements. This study was supported by funding from the Research Grants Council of HKSAR, China (CUHK450210), and Innovation and Technology Support Programme of HKSAR, China (ITS/152/11FP). The digital elevation model of the investigated zone was acquired through the SRTM archive. Original Envisat ASAR data are copyright of the European Space Agency. We also thank Prof. Yunpeng Wang and his research group from Guangzhou Institute of Geochemistry under the Chinese Academy of Sciences and Prof. Bernard de Jong from Utrecht University in Netherlands for their help and advice in the field-work of the Guangzhou urban areas in 2009 and 2010.

Edited by: R. Lasaponara

Reviewed by: Z. Li, F. Cigna, and another anonymous referee

\section{References}

Chen, F. L., Lin, H., Yeung, Y., and Cheng, S.: Detection of slope instability in Hong Kong based on multi-baseline differential SAR interferometry using ALOS PALSAR data, GISci. Remote Sens., 47, 208-220, 2010.

Costantini, M. and Rosen, P.: A generalized phase unwrapping approach for sparse data. Proceedings of IGARSS'99, Hamburg, Germany, June 28-July 2, 1, 267-269, 1999.

Farr, T. and Kobrick, M.: Shuttle Radar Topography Mission produces a wealth of data, AGU Eos, 81, 583-585, 2000.

Ferretti, A., Prati, C., and Rocca, F.: Permanent scatterers in SAR interferometry, IEEE Trans. Geosci. Remote Sens., 39, 8-20, 2001.

Ferretti, A., Fumagalli, A., Novali, F., Prati, C., Rocca, F., and Rucci, A.: A New Algorithm for Processing Interferometric Data-Stacks:SqueeSAR, IEEE Trans. Geosci. Remote Sens., 49, 3460-3470, 2011.

Fruneau, B. and Sarti, F.: Detection of ground subsidence in the city of Paris using radar interferometry: Isolation of deformation from atmospheric artifacts using correlation, Geophys. Res. Lett., 27, 3981-3984, doi:10.1029/2000GL008489, 2000

Glaeser, E.: Cities, productivity, and quality of life, Science, 333, 592-594, 2011.

Hilley, G. E., Burgmann, R., Ferretti, A., Novali, F., and Rocca, F.: Dynamics of slow-moving landslides from permanent scatterer analysis, Science, 304, 1952-1955, 2004.

Jonsson, S., Segall, P., Pedersen, R., and Bjornsson, G.: Postearthquake ground movements correlated to pore-pressure transients, Nature, 424, 179-183, 2003.

Karen, C. S., Robert, K. K., and Curtis, E. W.: Landsat revelas China's farmland reserves, but they're vanishing fast, Nature, 406, 121, doi:10.1038/35018267, 2000.

Kim, S. W., Wdowinski, S., Dixon, T. H., Amelung, F., Kim, J. W., and Won, J. S.: Measurements and predictions of subsidence induced by soil consolidation using persistent scatterer InSAR and a hyperbolic model, Geophys. Res. Lett., 37, L05304, doi:10.1029/2009GL041644, 2010.

Lanari, R., Mora, O., and Manunta, M.: A small-baseline approach for investigating deformations on full-resolution differential SAR interferograms, IEEE Trans. Geosci. Remote Sens., 42, 1377-1386, 2004.

Lin, H., Chen, F. L., and Zhao, Q.: Land deformation monitoring using coherent target-neighbourhood networking method combined with polarimetric information: a case study of Shanghai, China, Int. J. Remote Sens., 32, 2395-2407, 2011.

Meckel, T. A., Brink ten, U. S., and Williams, S. J.: Current subsidence rates due to compaction of Holocene sediments in southern Louisiana, Geophys. Res. Lett., 33, L11403, doi:10.1029/2006GL026300, 2006.

Raucoules, D., Parcharidis, I., Feurer, D., Novalli, F., Ferretti, A., Carnec, C., Lagios, E., Sakkas, V., Le Mouelic, S., Cooksley, G., and Hosford, S.: Ground deformation detection of the greater area of Thessaloniki (Northern Greece) using radar interferometry techniques, Nat. Hazards Earth Syst. Sci., 8, 779-788, doi:10.5194/nhess-8-779-2008, 2008.

Steven, W. E., Colin, M., and William, S.: Geology and geological hazards of the Auckland urban area, New Zealand, Quat. Int., 103, 3-21, 2003.

Stone, R.: Macau launches late bid to cure its Pearl River Delta 
blues, Science, 324, 1373-1374, 2009.

Stramondo, S., Bozzano, F., Marra, F., Wegmuller, U., Cinti, F. R., Moro, M., and Saroli, M.: Subsidence induced by urbanisation in the city of Rome detected by advanced InSAR technique and geotechnical investigations, Remote Sens. Environ., 112, 31603172, 2008.

Teatini, P., Tosi, L., Strozzi, T., Carbognin, L., Wegmuller, U., and Rizzetto, F.: Mapping regional land displacements in the Venice coastland by an integrated monitoring system, Remote Sens. Environ., 98, 403-413, 2005.

Terzaghi, K. and Peck, R. B.: Soil mechanics in engineering practice, John Wiley \& Sons, 1967.

Tizzani, P., Berardino, P., Casu, F., Euillades, P., Manzo, M., Ricciardi, G. P., Zeni, G., and Lanari, R.: Surface deformation of Long Valley caldera and Mono Basin, California, investigated with the SBAS-InSAR approach, Remote Sens. Environ., 108, 277-289, 2007.
Weng, Q.: A historical perspective of river basin management in the Pearl River Delta of China, J. Environ. Manage., 85, 1048-1062, 2007.

Zebker, H., Rosen, P., Goldstein, R., Gabriel, A., and Werner, C.: On the derivation of coseismic displacement fields using differential radar interferometry: The Landers earthquake, J. Geophys. Res., 99, 19617-19643, 1994.

Zeng, N., Ding, Y., Pan, J., Wang, H., and Gregg, J.: Climate change-the Chinese challenge, Science, 319, 730-731, 2008.

Zhao, Q., Lin, H., Jiang, L., Chen, F. L., and Cheng, S.: A study of ground deformation in the Guangzhou urban area with persistent scatterer inferferometry, Sensors, 9, 503-518, 2009.

Zhu, Z., Xie, J., Zhang, J., Liang, H., Qiu, Y., Xia, Z., Ling, Q., Lin, J., and Zhou, H.: Characteristics of geological hazards in South China coastal areas and impact on regional sustainable development, Int. J. Sust. Dev. World, 14, 421-427, 2007. 